\title{
Psychosocial factors and Burnout Syndrome among mental health professionals*
}

\author{
Amanda Sorce Moreira ${ }^{1}$ \\ (D) https://orcid.org/0000-0002-5050-4261 \\ Sergio Roberto de Lucca ${ }^{1}$ \\ (1D) https://orcid.org/0000-0001-6023-0949
}

* Paper extracted from master's thesis "Fatores psicossociais e síndrome de burnout entre os profissionais dos serviços de saúde mental", presented to Universidade Estadual de Campinas, Faculdade de Ciências Médicas, Campinas, SP, Brazil."

1 Universidade Estadual de Campinas, Faculdade de Ciências Médicas, Campinas, SP, Brazil.
Objective: to identify biopsychosocial factors at work associated with the Burnout Syndrome in mental health professionals. Method: a cross-sectional study with a quantitative approach conducted with a sample of 293 mental health service workers from the public network of a municipality in the inland of the state of São Paulo, Brazil. An instrument composed of three selfadministered questionnaires was applied, namely: biosocial data form, the Job Stress Scale (JSS) and the Maslach Burnout Inventory (MBI- HSS). The data were analyzed through the application of the Chi-squared and logistic regression tests, with the adoption of a 5\% significance level. Results: Burnout Syndrome prevalence was $7 \%$ with a predominance of nursing professionals and was associated with the work sector, the use of psychotropic drugs, low satisfaction with the manager and with the low control over the work activity. Among the professionals with Burnout Syndrome, twelve performed functions considered of high wear, six performed passive work and two were in low wear activity. Conclusion: low control was the main psychosocial factor at work associated with Burnout Syndrome, making it necessary to develop actions that promote worker autonomy and improve the management of stress-triggering psychosocial factors.

Descriptors: Occupational Stress; Burnout, Professional; Mental Health; Health Personnel; Professional Autonomy; Social Support.

\section{How to cite this article}

Moreira AS, de Lucca SR. Psychosocial factors and Burnout Syndrome among mental health professionals. Rev. Latino-Am. Enfermagem. 2020;28:e3336. [Access DOI: http://dx.doi.org/10.1590/1518-8345.4175.3336. ]; Available in:

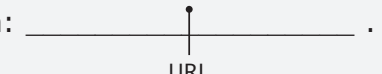
URL 


\section{Introduction}

The inclusion of the Unified Health System (Sistema Único de Saúde - SUS - in Portuguese language) principles in the 1988 Constitution broadened perspectives on the Psychiatric Reform movement, resulting in a network of mental health care and assistance capable of offering home care, outpatient and hospital care, Psychosocial Care Centers (Centros de Atenção Psicossocial, - CAPS - in Portuguese language) and Home Therapeutic Services (Serviços Residenciais Terapêuticos - SRT - in Portuguese language $)^{(1)}$.

The work of the professionals in these services is complex and depends on the articulation of multidisciplinary teams, evolving different knowledge, practices and experiences ${ }^{(2)}$. These workers experience intense and antagonistic feelings, often conflicting, in addition to the high resoluteness charges, work overload and precarious working conditions, which may compromise their health(3).

In this context, chronic exposure to stressors in the work environment has as one of the negative outcomes the Burnout Syndrome (BS). The syndrome mainly affects professionals in services dealing directly with people and results from the interaction between psychosocial factors and individual characteristics(4).

In addition to the peculiarities of mental health work, professionals in these services are more exposed to situations of violence because they deal with patients in acute crisis and who require help and permanent supervision ${ }^{(5)}$.

Psychosocial factors, work-related stress, violence and (moral and/or sexual) harassment are, currently, the greatest challenges in the field of occupational health and safety ${ }^{(6)}$. The Psychosocial factors at work (Fatores Psicossociais no Trabalho - FPT- in Portuguese language) arise from the interactions between the worker and the work environment, working conditions and organization, work demands and the degree of autonomy over activities and they can influence health, performance and job satisfaction ${ }^{(7)}$.

Among the instruments for evaluating these factors, it is the Demand-Control-Social Support model, which checks the relationship between psychological demands and the degree of control in work activities with potential for stress and exhaustion ${ }^{(8)}$. This model establishes that work processes with high demands and low control have a greater potential for illness, while social support would play a mediating role in this relationship( ${ }^{(9)}$.

Studies on FTPs and BS in mental health service's professionals are still scarce in the literature. Thus, considering the recognized emotional burden and stress in these services, this study sought to identify the biopsychosocial factors at work associated with BS in mental health professionals.

\section{Method}

An epidemiological, cross-sectional, and descriptive study with a quantitative approach conducted with a sample of professionals from a mental health service provided by a public institution, located in Casa Branca, a municipality of the inland of São Paulo, Brazil, in the period from January to February 2019.

The criteria for choosing the institution and sample selection were based on the particular characteristics of the teams regarding the direct and indirect care given to patients with mental disorders, previously, observed by the researchers during the non-participating observation stage in the three work shifts, in order to know and contextualize the work particularities of the respective services.

The institution is a regional reference in mental health care for eleven municipalities, offering longstay admission services with a female, male, and geriatric quarters, outpatient care, and short-term admission through the type III Center for Psychosocial Care (CAPS III), and thirty homes that comprise the Therapeutic Residency Services (Serviços de Residências Terapêuticas - SRT - in Portuguese language). All care services are full time and professionals work in three fixed shifts (morning, afternoon and evening), while administrative professionals work from Monday to Friday, from 7:00 a.m. to 2:00 p.m. The institution had 547 professionals, 405 from the care sector and 142 from the administrative sector, including managers.

As inclusion criteria for the survey, all care and administrative professionals, who had been active in the institution for more than six months, were included. Those who were on days off, holidays, away on medical or maternity leave, who were not found after three attempts of contact and those who filled in incompletely the data collection instrument were excluded.

The sampling process was carried out using the convenience non-probabilistic method, resulting in a sample of 293 professionals, since 58 participants did not meet the inclusion criteria, 23 refused to participate in the survey and 173 did not return the instrument.

The data were collected using a self-completion instrument, composed of three questionnaires: the biosocial questionnaire, prepared by the authors and based on relevant studies on the topic $(8,10-11)$, the Job 
Stress Scale (JSS), a short version of the Demand and Control model and the Maslach Burnout Inventory Human Services Survey (MBI-HSS). The instrument was pre-tested by the researchers in a group of ten professionals from different shifts.

The biosocial questionnaire was composed of 27 multiple-choice questions on gender, marital status, age, race/color, disabilities, dependents, schooling, place and sector of work, position/function, working time in this institution and in the current position, working hours, shifts, overtime, the occurrence of harms to health (accidents and occupational illness) and moral and/or sexual harassment, use of psychotropic, alcohol and other drugs, satisfaction with the work, the institution, the manager and coworkers, and what this employee, would possibly, change in this service.

Questions about position/function, accidents at work, and work-related illnesses were semi-open so that participants could report their answers. In order to evaluate the perception of satisfaction, we chose not to apply specific instruments, because they do not match the objectives of the research. The participants should mark zero, five, or ten for low, moderate, and high satisfaction respectively. In addition, on the question of suggested changes, participants could point out more than one alternative and, also, describe other changes that were not listed by the researchers.

The MBI-HSS is a three-dimensional questionnaire intended for health professionals(12), translated into and validated for Portuguese ${ }^{(11)}$, consisting of 22 multiple-choice questions, 9 concerning the dimension of emotional exhaustion (EE), 5 concerning depersonalization (DE) and 8 concerning low personal fulfillment $(\mathrm{PF})^{(11-12)}$. Responses vary according to their frequency of occurrence and to each one, the following points are assigned: "never", gets zero, "a few times a year", 1 point, "a few times a month", 2 points, "a few times a week", 3 points, and "daily", 4 points. At the end of the sum of each dimension, the score is estimated by calculating the quartiles(11). Cases with high $\mathrm{EE}$ and DE and low PF, concomitantly are considered as indicative of Burnout ${ }^{(11-12)}$.

The Job Stress Scale (JSS) or "Swedish DemandControl-Social-Support Scale" is a three-dimensional Likert-type scale that assesses psychosocial factors and risk of stress in work activities ${ }^{(8,13)}$, translated into and validated for Portuguese ${ }^{(8)}$, composed of 17 questions, of which 5 are about psychological demand, 6 about task control and 6 about social support. For the demand and control dimensions, the responses vary according to the frequency of occurrence, and the following points are assigned to each one: "often", 4 points, "sometimes", 3 points, "rarely" gets 2 points, and "never/almost never", 1 point. In the social support dimension, for the statement "I totally agree", 4 points are given, "I agree more than I disagree", 3 points, "I disagree more than I agree", 2 points, and "I totally disagree", 1 point. At the end of the sum of the three dimensions, the median is calculated; this analysis allows working conditions to be classified in the quadrants of the model: active work, passive work, low demand work, and high demand work ${ }^{(8)}$.

The collected data were analyzed by means of descriptive statistics and presented in the form of frequency tables with absolute ( $\mathrm{n}$ ) and percentage (\%) values. All independent variables were tested, both for the occurrence of BS and for comparison between sectors. The Chi-squared test was used for comparison between the sectors and, for the Odds Ratio estimate for the occurrence of Burnout, the simple and multiple Logistic Regression analyses, adjusted by stepwise selection criteria, were used. The Statistical Analysis System (SAS) program, version 9.4, was used.

All ethical principles of research with human beings were respected and the study was submitted to and approved by the local Ethics Research Committee (CEP), under the following opinion CAAE No.: 93599118.0.0000.5404, on September 26th, 2018.

\section{Results}

In this study, there was a predominance of female workers $(64.8 \%)$, aged 45 years old or older $(66.3 \%)$, who had a partner $(62.5 \%)$, children $(59.4 \%)$ and no dependents $(74.7 \%)$. There were no differences between the percentages of participants with basic education level (Elementary and Secondary - 50.9\%) and higher education level (Higher and Graduation - 49.1\%).

Most of the participants $(87.4 \%)$ worked in the long-term service, in care activities, distributed among the positions of auxiliary and nursing technician (150), nurse (13), doctor (5), dentist (1), health and therapeutic function assistant (16) and health care technical agents (psychologist, social worker, occupational therapist, physiotherapist, pharmacist and pharmacy technician).

Among those who performed exclusively administrative activities (29.7\%), 12 held the posts of health officers, seven administrative officers, eight chief of health, and two health directors. Some other 55 professionals in the function of general services assistant, worked in the laundry, kitchen, 
janitorial, warehouse, electric maintenance, agriculture/ gardening, and three drivers.

There was a predominance of professionals working in the morning $(60.8 \%)$, due to the working hours of both (care and administrative) sectors, with working hours of up to 30 hours per week (91.8\%). The professionals who worked overtime, mostly, worked in the night shift. About one third of the participants reported having a second job.

The alcohol consumption was self-reported by $58 \%$ of the subjects and $28 \%$ reported the use of psychotropic and illicit drugs. Regarding work-related diseases, 53 professionals reported the occurrence of Musculoskeletal System diseases and 33 participants reported Mental and Behavioral Disorders. Among the professionals in the assistance, moral and/ or sexual harassment was reported by $32 \%$ of the participants.

As for job satisfaction, $48 \%$ of the participants were satisfied with their co-workers and management, while $62.4 \%$ expressed a moderate satisfaction degree with the institution.

Among the factors of dissatisfaction, the subjects reported the lack of career planning, bonuses and awards, inadequate ergonomic conditions and difficulties in relationships between team members.

Regarding the psychosocial factors, considering the means and medians obtained in the psychological demands and control dimensions, it was possible to classify and distribute the work activities in the DemandControl model, as described in Figure 1.

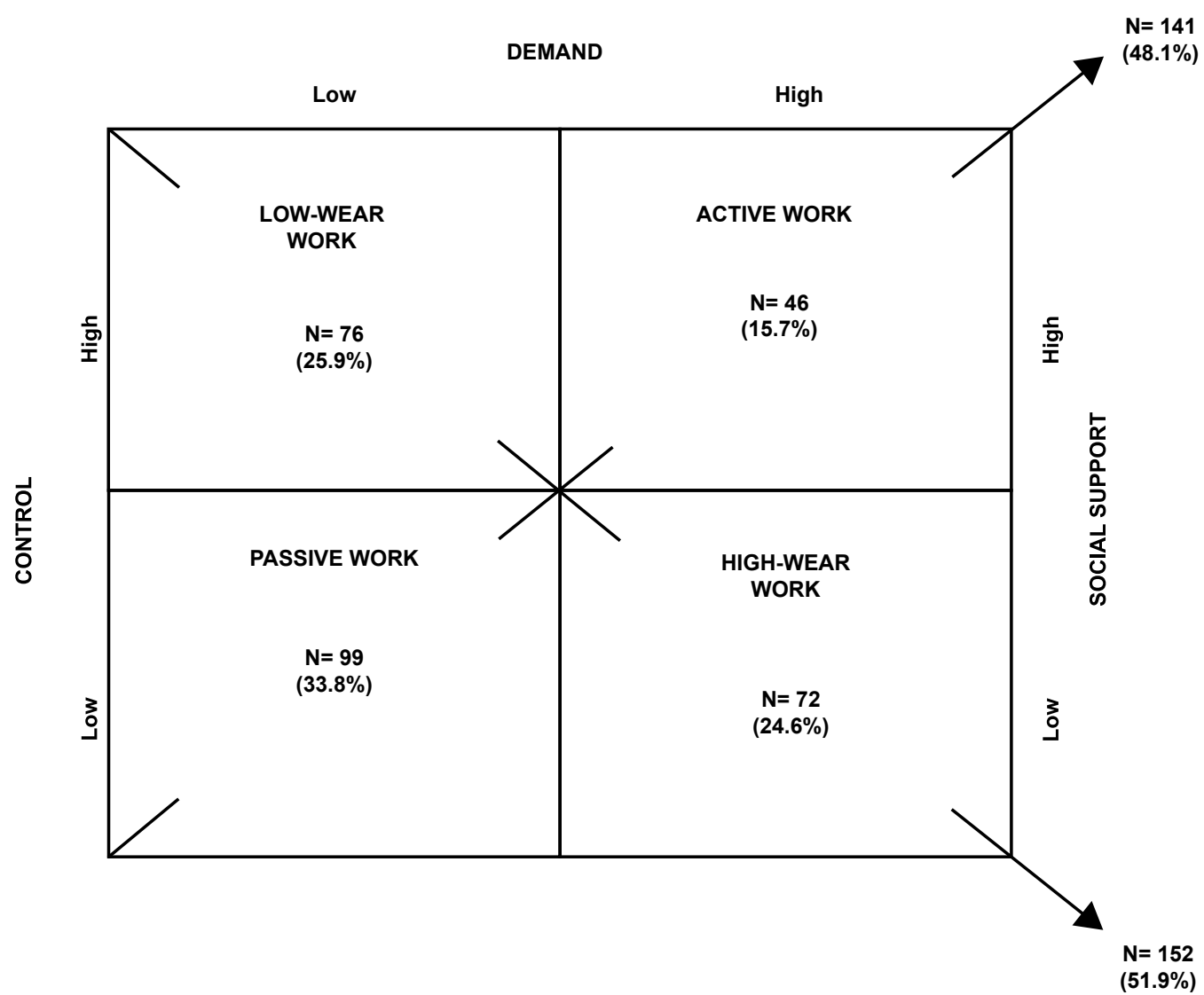

Figure 1 - Distribution of the workers $(n=293)$ according to the Demand-Control-Social Support Model. Casa Branca, SP, Brazil, 2019

The data in Figure 1 showed that $33.8 \%$ of the participants worked in activities with low demands and control and low social support (passive work). In relation to the administrative workers, $27.6 \%$ performed high-wear work activities, $26.4 \%$ passive work, $25.3 \%$ active work, and $20.7 \%$ low-wear work. On the other hand, of the care professionals, $36.9 \%$ carry out passive work activities, $28.1 \%$ low-wear work, $23.3 \%$ highwear work, and $11.7 \%$ active work. Social support was more prevalent among administrative workers (62\%), compared to care workers (42.2\%). The "psychological demands" $(p=0.004)$ and "social support" $(p=0.001)$ dimensions showed statistical associations between the sectors wherein these professionals were inserted.

The MBI descriptive analysis, obtained through the quartile distribution, showed that most workers in these mental health services had moderate EE, low DE, and moderate PF, as described in Table 1. 
Table 1 - Distribution of the workers' frequency $(n=293)$ according to the cut-off points of the MBI- HSS dimensions' quartiles. Casa Branca, SP, Brazil, $2019(n=293)$

\begin{tabular}{lccc}
\multicolumn{1}{c}{ Dimension } & Cut-off points & N & (\%) \\
\hline Emotional Exhaustion (EE) & & & \\
- Low & $\leq 7$ & 74 & 25.26 \\
- Moderate & $8-19$ & 141 & 48.12 \\
- High & $\geq 20$ & 78 & 26.62 \\
Depersonalization (DE) & & & \\
- Low & $=0$ & 140 & 47.78 \\
- Moderate & $1-4$ & 68 & 23.21 \\
- High & $\geq 5$ & 85 & 29.01 \\
Personal Fulfillment (PF) & & & \\
- Low & $\leq 23$ & 88 & 30.03 \\
- Moderate & $24-30$ & 119 & 40.61 \\
- High & $\geq 31$ & 86 & 29.35 \\
\hline
\end{tabular}

The prevalence of BS among the professionals who presented, concomitantly, high $\mathrm{EE}$, high $\mathrm{DE}$, and low PF was $7 \%$ (20 professionals), with predominance among the care workers $(p=0.039)$, in the function of nursing assistants $(p=0.039)$.

It was verified that most administrative workers had moderate EE and low PF. The percentages of these professionals with low (40.2\%) and high (39\%) depersonalization were very close. Among the care professionals, the majority had moderate EE and PF and low DE. Only the EE dimension did not show a statistical difference between sectors (DE: $p=0.046$; PF: $p=0.003$ ).

The study variables associated with the Burnout Syndrome $(p<0.05)$ and with the respective odds ratio for the illness of these mental health service professionals are described in Table 2.

Table 2 - Gross Odds Ratio of the Burnout Syndrome in mental health professionals $(n=293)$ according to biosocial and work characteristics and the psychosocial factors at work. Casa Branca, SP, Brazil, 2019

\begin{tabular}{|c|c|c|c|c|}
\hline Variable & Category & p-value & OR & 95\% Confidence Interval \\
\hline Schooling & Elementary and High $\mathrm{x}$ Higher & 0.044 & 2.92 & $1.02 ; 8.34$ \\
\hline Use of psychotropic drug & Yes $\times$ No & 0.028 & 2.79 & $1.16 ; 6.98$ \\
\hline Time in the sector & $\leq 5$ years $x>5$ years & 0.028 & 3.02 & $1.12 ; 8.09$ \\
\hline Accident at work: Aggression & Yes $\times$ No & 0.029 & 2.96 & $1.11 ; 7.85$ \\
\hline $\begin{array}{l}\text { Satisfaction in relation to: } \\
\text { - Work } \\
\text { - Institution } \\
\text { - Co-worker } \\
\text { - Management }\end{array}$ & $\begin{array}{l}\text { High } \times \text { Low } \\
\text { High } \times \text { Low } \\
\text { High } \times \text { Low } \\
\text { High } \times \text { Low }\end{array}$ & $\begin{array}{l}0.010 \\
0.038 \\
0.043 \\
0.007\end{array}$ & $\begin{array}{c}5.00 \\
3.16 \\
4.76 \\
12.00\end{array}$ & $\begin{array}{c}1.46 ; 17.09 \\
1.06 ; 9.41 \\
1.04 ; 21.7 \\
3.07 ; 46.88\end{array}$ \\
\hline Desire for changes: Management profile & Yes $\times$ No & 0.045 & 2.56 & $1.01 ; 6.46$ \\
\hline Control & Greater x Minor & 0.009 & 7.05 & $1.60 ; 31.01$ \\
\hline Social Support & Greater x Minor & 0.014 & 4.02 & $1.31 ; 12.36$ \\
\hline
\end{tabular}

The multiple analysis confirmed the association of the following variables: schooling $[\mathrm{OR}=5.50 ; 95 \%$ CI $(1.29 ; 23.33)]$, work sector $[\mathrm{OR}=18.37 ; 95 \% \mathrm{CI}$ $(3.85 ; 87.48)]$, use of de psychotropic $[O R=5.21$; $95 \%$ CI $(1.38 ; 19.98)]$, satisfaction with the management $[\mathrm{OR}=40.46 ; 95 \%$ CI $(5.63 ; 29.05)$ ] and control over work activities $[\mathrm{OR}=11.71 ; 95 \% \mathrm{CI}$ $(2.50 ; 11.2)]$.

For the analysis of the association of the JSS and MBI scales' dimensions, the low demand, high control and high social support variables were used as a reference. Table 3 describes such associations and the gross odds ratios for the occurrence of high EE, high DE, and low PF.

In the multiple analysis, there has been association between high DE and work demand $[\mathrm{OR}=3.43$; 95\% CI $(1.87 ; 6.30)]$, while low PF was associated with control $[\mathrm{OR}=2.34 ; 95 \% \mathrm{CI}(1.17 ; 4.67)]$ and social support $[O R=2.77 ; 95 \%$ CI $(1.40 ; 5.46)]$.

Figure 2 illustrates the distribution of the number of professionals with Burnout in the respective quadrants of the Demand-Control-Social Support model.
Table 3 - Gross Odds Ratio between the dimensions from the stress scale at work with high Emotional Exhaustion $(E E)$, high Depersonalization (DE), and low Personal Fulfilment (PF). Casa Branca, SP, Brazil, 2019

\begin{tabular}{|c|c|c|c|}
\hline \multirow{2}{*}{ Dimension } & \multicolumn{3}{|c|}{ High Emotional Exhaustion (EE) } \\
\hline & p-value & Gross OR & $95 \%$ Confidence Interval \\
\hline Demand & 0.001 & 10.22 & $4.64 ; 22.52$ \\
\hline Control & 0.037 & 2.01 & $1.04 ; 3.14$ \\
\hline \multirow[t]{3}{*}{ Social Support } & 0.001 & 4.43 & $2.24 ; 8.76$ \\
\hline & \multicolumn{3}{|c|}{ High Depersonalization (DE) } \\
\hline & p-value & Gross OR & $95 \%$ Confidence Interval \\
\hline Demand & 0.002 & 3.24 & $1.84 ; 5.70$ \\
\hline Control & 0.793 & 1.14 & $0.66 ; 1.99$ \\
\hline \multirow[t]{3}{*}{ Social Support } & 0.407 & 1.41 & $0.82 ; 2.43$ \\
\hline & \multicolumn{3}{|c|}{ Low Personal Fulfillment (PF) } \\
\hline & p-value & Gross OR & $95 \%$ Confidence Interval \\
\hline Demand & 0.044 & 2.18 & $1.78 ; 4.04$ \\
\hline Control & $\begin{array}{l}0.006 \\
0.022\end{array}$ & $\begin{array}{l}1.90 \\
2.34\end{array}$ & $1.01 ; 3.57$ \\
\hline Social Support & 0.035 & 2.20 & $1.02 ; 4.04$ \\
\hline
\end{tabular}




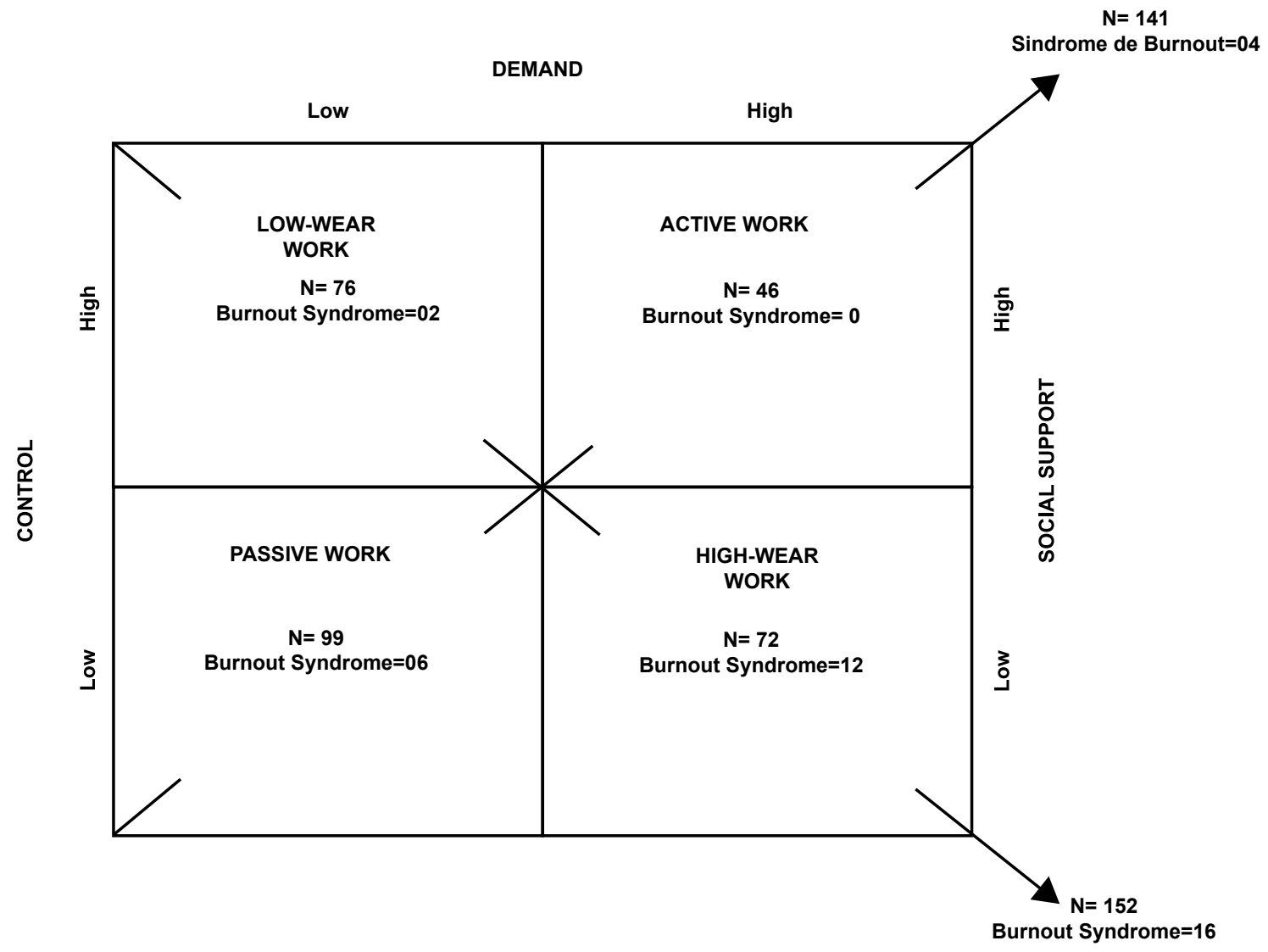

Figure 2 - Distribution of the number of professionals $(n=293)$ with Burnout Syndrome according to the classification of work and based on the Demand-Control-Social Support model. Casa Branca, SP, Brazil, 2019

\section{Discussion}

Identifying the main psychosocial factors that trigger stress at work among mental health professionals is crucial to understand the stress and BS triggers in these services since the diagnosis of the situation can help in the development of strategies to promote and protect workers' health in the context of work organization.

Although there is no consensus in the literature on the interpretation of results for determining the prevalence of the Burnout Syndrome, which varies between 5.0 and $55.3 \%$, depending on the analysis criteria adopted, a percentage of $7 \%$ was observed in this population, proportional to that found in studies with health professional(14).

In the isolated analysis of the dimensions, $26.6 \%$ of the participants presented high emotional exhaustion, $29.0 \%$ high depersonalization and 30\% low professional fulfillment. These results were similar to other studies that resulted in the prevalence of high emotional exhaustion between $17.2 \%$ and $53.3 \%$; high depersonalization (DE) between $17.8 \%$ and $93.7 \%$ and low personal fulfillment (PF) between $18.8 \%$ and $93.7 \%{ }^{(14)}$.

Biosocial characteristics do not always show an association with the three dimensions that conceptualize the BS, but they may present association with some dimension. Research with professionals from a psychiatric hospital in Australia showed that Burnout was associated with gender (female vulnerability), age (under 45), and sector of work (contact with the patient)(15-16). In fact, the care process peculiar aspects contribute to the feminization of some occupations and professions, as observed in the health sector ${ }^{(15)}$.

The low turnover and stability of professionals in the public mental health institution surveyed may justify the higher prevalence of the syndrome among those over 45 years old found in this study.

As evidenced by other authors, the shorter time in the sector was another factor associated with Burnout. Workers with less time in the institution or sector are more likely to develop the syndrome due to the difficulties of insertion into the group, feeling of insecurity, job instability associated with the need for acceptance $^{(17)}$. Workers at the beginning of their career are more likely to manifest the syndrome because they perceive higher the interpersonal demands at work ${ }^{(18)}$.

The relationship between Burnout Syndrome and psychic diseases is controversial, but researchers consider the syndrome as a risk factor for the consumption of antidepressants(19). This study showed an association between the consumption of psychotropic 
drugs and professional exhaustion, while having mental and behavioral disorders resulting from work was associated with high emotional exhaustion(20).

Professionals who suffer physical aggression from patients are more vulnerable to emotional exhaustion and also to $\mathrm{BS}^{(21)}$. In addition to professional exhaustion, professionals who have already suffered aggression also have greater dissatisfaction, work overload and low commitment, in addition to increasing work turnover (22).

The association between job satisfaction and Burnout is scientifically proven and it suggests that both low satisfaction can cause work exhaustion and as burnout can be the cause of dissatisfaction(23-24). In this study, the low satisfaction or indifference of professionals in relation to the institution, the work, the co-workers and the management proved to be associated with BS and some of its dimensions.

Professionals with worse Burnout psychic symptoms have lower job satisfaction, specially, the younger ones(24). A survey showed that multi-professional teams in a psychiatric hospital were dissatisfied with the lack of autonomy and participation in decision-making within the service regarding financial issues and benefits, and were moderately overloaded ${ }^{(25)}$.

Dissatisfaction with management, with the lack of professional growth and benefits can increase symptoms of emotional exhaustion, depersonalization and, consequently, of Burnout(25-27). These factors also presented an association with the syndrome, resembling a study with psychiatric professionals in Greece ${ }^{(27)}$.

It is evident that each job has its own characteristics and that each worker understands these factors in a subjective way, and it is this perception that modulates the levels of Burnout(26).

The types of tasks influence the worker's perception of physical and psychological demands and of the work process, with direct patient care being recognized as the most demanding in health services and may be perceived as rewarding or not. The task of dealing with documents, on the other hand, is less rewarding, although professionals recognize it as a work of less demand and greater control ${ }^{(28)}$.

High work demands, low control over the work process and lack of social support significantly influence satisfaction(21,29-30). A study on the interaction of the psychosocial factors with the Burnout dimensions showed that the psychological demand was the one most related to emotional exhaustion, while control over the work process was more associated with depersonalization and personal fulfillment ${ }^{(31)}$. Besides, the authors also found that the interaction between demand, control and social support was significant for the occurrence of emotional exhaustion and depersonalization ${ }^{(31)}$.
The predominance of BS among professionals who perform high-wear activities coincides with those of other researches, which shows that Burnout is related to the lack of autonomy, high workloads, the performance of multiple functions and low social support ${ }^{(32-33)}$. Other studies indicate that both high psychological demands at work and low control over work activities are often associated with Burnout; however, over time, high demands seem to be more associated with the syndrome than with low control over the work process( ${ }^{(34)}$.

Emotional exhaustion is the dimension of professional exhaustion most strongly influenced by work psychosocial factors and the work demand is the dimension of stress most related to this factor ${ }^{(26,35-36)}$. The associations between emotional exhaustion, work demand, and low satisfaction suggest that the worker with high exhaustion tends to perceive higher psychological demand and fatigue ${ }^{(37)}$. The data observed among administrative professionals in this study are similar to such statement. However, although there is a difference between the levels of work demands and of Burnout, between the care and administrative sectors, the severity of these factors differ little, even when health professionals tend to report a greater workload(37).

Research on the relationship between work demands and low personal fulfillment is still scarce (38); however, in the aforementioned survey, there was an association between them, with the odds ratio estimated at 1.53 .

Studies performed to estimate Burnout risk, due to exposure to psychosocial factors at work showed that, besides the low control being associated with the syndrome, the chances of having high emotional exhaustion in these situations were $1.63^{(38)}$, similar to the data obtained in this research.

Autonomy is considered a mediator of psychological wear ${ }^{(39)}$. The lower the control over the work process, the greater the emotional exhaustion, independently from the work load(22), that is, having more control over the work protects the worker from exhaustion.

Some studies indicate that low control and low social support increase the chances of having $\mathrm{BS}^{(5,21,31,36)}$. However, acting only on these factors may not diminish the chances of illness, because it is not enough just to improve social interaction at work and promote greater autonomy; it is necessary, fundamentally, to reduce the high psychological demands to which these professionals are subjected for the effective reduction in the work environment ${ }^{(40)}$.

We observe that the worker exposed to high-wear situations does not always have greater exhaustion since the three dimensions of the syndrome relate differently to the main psychosocial factors (demand, 
control, and social support)(36). Another study also found an association of the emotional exhaustion and personal fulfillment dimensions with all the psychosocial dimensions, as well as the association of depersonalization with the psychological demand and social support dimensions ${ }^{(41)}$.

Most studies found no association between low social support and depersonalization, but we believe that high social support reduces the chances of manifesting such a dimension ${ }^{(38)}$.

Professionals in active working conditions and high social support prove to be more personally fulfilled than those in the same working conditions, despite the low social support ${ }^{(36)}$. Among the workers in this study, it was observed that the administrative professionals had greater social support while care workers reported low support. This situation suggests that in the care sector there were more interpersonal problems than in the administrative sector, reinforcing the idea that the profile of the management, colleagues and work organization reflects on the quality of social support and increases the chances of having BS.

The distribution of workers in this study regarding the type of work, considering the level of psychological demand and control over the work process, was equivalent to a study on the evaluation of occupational stress in care and administrative workers at a university. Both showed that most workers were exposed to low demand and low control situations, configuring it passive work, followed by low-wear work ${ }^{(42)}$.

As already observed in another research ${ }^{(43)}$, both care and administrative sectors can be classified as passive work. The prevalence of mental health service's care workers in the passive work scenario can be explained by the fact that most of them are nursing auxiliaries and technicians, not performing managerial functions, which supposedly offer greater control over the work process ${ }^{(44)}$.

A survey pointed out the predominance of technical-administrative workers in situations of passive work, followed by low demand work, high demand work, and active work ${ }^{(45)}$. In this study, the predominance of Burnout has occurred in high-wear situations. This divergence between research may be associated with distinct institutional characteristics since one occurred in a university and the other in a public mental health care institution. However, the social support factor presented a similar distribution in both pieces of research and the technical-administrative professionals received high social support(45).

The predominance of care professionals in work situations is common in the literature ${ }^{(46)}$, although there is evidence that these workers may also be exposed to low-wear situations ${ }^{(40,47)}$ and active work $^{(48)}$. However, the percentage of workers exposed to high wear between the studies were similar(40,46-48).

In this survey, two professionals who performed managerial functions fell ill in a situation of low wear, results similar to those of a survey with health managers, in which a great concentration of these professionals was observed in these same work situations( ${ }^{(44)}$.

Passive work is considered the second biggest cause of illness, because in these situations the professional may manifest disinterest in the work and lose skills ${ }^{(46)}$. As well as in another study, this research also found cases of Burnout in care professionals exposed to passive work $^{(48)}$. Social support serves as a buffer against illness in passive work situations since, working in situations of low control and low demand, but receiving support, reduces the chances of having $\mathrm{BS}^{(47)}$.

Exposure to high-wear work associated with low social support can result in high exhaustion ${ }^{(31)}$. Unlike this study, some researchers found a higher prevalence of nurses in situations of low control and high demands arising from work in intensive care units ${ }^{(49)}$.

On the other hand, the highest prevalence of BS in mental health service workers was in high-wear work situations, similar to other studies that also related professional burnout to high-wear activities(48-49).

Thus, this reinforces the need to implement permanent strategies for identifying psychosocial factors to reduce work stress, in order to minimize the risk of professional burnout, to avoid new cases and the worsening of the sick who continue working(50).

The study was unprecedented in Brazil since it took place in a public mental health institution, provider of several services (long-term admission, CAPS III and $\mathrm{SRT}$ ), covering multiple (administrative and care) sectors and positions. Also, this research contributed to better describe the relationships in the subgroups investigated with the Burnout Syndrome and the psychosocial factors with the potential to trigger stress at work.

In cross-sectional studies, data on exposure and outcome are collected simultaneously, which makes inferences on causality impossible, although there is significant evidence to support such association. Since this is a convenience sample and considering the heterogeneity of this population, the results of this study present limitations regarding its potential for generalization and comparison, due to the peculiarities of each institution and biopsychosocial and occupational factors. In addition, the representativeness of the sample and the high non-response rate (non-response bias) may overestimate or underestimate the results. Other probable limitations were the memory bias due to the instrument's self-reporting and the healthy worker bias, common in this type of research. 


\section{Conclusion}

The present study identified a $7 \%$ prevalence of the Burnout Syndrome among mental health service professionals, mainly among female nursing professionals (auxiliaries and technicians), older than 45 years of age, and with less time working in the institution and in the sector.

There were associations of the syndrome with the work sector, the use of psychotropic drugs, low satisfaction with the manager, and low control at work. Most of the Burnout cases ran among the professionals in work situations called high-wear work, characterized by high work demand and low autonomy.

The work activities with high psychological demands and low control over the tasks were the main psychosocial factors associated with the Burnout Syndrome. Thus, more detailed studies are needed, with a deepening of individual and organizational factors, to develop ways of working that make it possible to minimize the impacts on the health of workers in mental health services.

\section{Acknowledgments}

To all the professionals of the research institutions, especially Valmir and Juliana for their support and collaboration in the data collection phase.

\section{References}

1. Amarante $P$, Nunes MO. Psychiatric reform in the SUS and the struggle for a society without asylums. Ciênc Saúde Coletiva. 2018 June;23(6):2067-74. doi: https:// doi.org/10.1590/1413-81232018236.07082018

2. Prince $M$, Prina $M$, Guerchet $M$. Journey of Caring: An analysis of long-term care for dementia. World Alzheimer Report 2013. [Internet]. 2013 [cited Sept 15, 2019]. Available from: https://www.alz.co.uk/research/worldreport-2013

3. Vasconcellos VC, Azevedo C. Mental health work: professional's experiences facing the outcomes. Psicol Estudo. 2012 Oct-Dec;17(4):659-68. doi: http://dx.doi. org/10.1590/S1413-73722012000400012

4. Pêgo FPL, Pêgo DR. Burnout Syndrome. Rev Bras Med Trab. 2016 Nov;14(2):171-6. doi: http://dx.doi. org/10.5327/Z1679-443520162215

5. Paula GS, Oliveira EB, Silva AV, Souza SRC, Fabri JMG, Guerra OA. Work-related violence in psychiatry in the perception of nursing workers. Rev Eletr Saúde Mental Álcool Drogas. 2017 Jan;13(2):86-92. doi: http://dx.doi. org/10.11606/issn.1806-6976.v13i2p86-92

6. Leka S, Wassenhove WV, Jain A. Is psychosocial risk prevention possible? Deconstructing common presumptions. Safety Science. 2015 Apr;71:61-7. doi: http://dx.doi.org/10.1016/j.ssci.2014.03.014

7. International Labour Organization. Psychosocial factors at work: recognition and control. Report of the Joint ILO/ WHO Committee on Occupation Health. Ninth Session, Geneva, 18-24 Sept 1984. Geneva. [Internet]. 1986 [cited May 12, 2019]. Available from: https://www.who. int/occupational_health/publications/ILO_WHO_1984_ report_of_the_joint_committee.pdf

8. Alves MGM, Chor D, Faerstein E, Werneck GL, Lopes CS. Job strain and hypertension in women: Estudo PróSaúde (Pro- Health Study). Rev Saúde Pública. 2009 Apr;43(5):1-4. doi: http://dx.doi.org/10.1590/S003489102009000500019

9. Bakker AR, Costa PL. Chronic job burnout and daily functioning: A theoretical analysis. Burnout Res. 2014 Apr;1:112-9. doi: http://dx.doi.org/10.1016/j. burn.2014.04.003

10. Zanatta AB, Lucca SR. Prevalence of Burnout syndrome in health professionals of an onco-hematological pediatric hospital. Rev Esc Enferm USP. 2015 Jan 12;49(2):253-60. doi: http://dx.doi.org/10.1590/S0080623420150000200010

11. Lautert L. Professional fatigue: empirical study with hospital nurses. Rev Gaucha Enferm. [Internet]. 1997 [cited May 10, 2019];18(2):133-44. Available from: https://seer.ufrgs.br/RevistaGauchadeEnfermagem/ article/view/4135/42822

12. Maslach C, Jackson SE, Leiter MP. Maslach Burnout Inventory. [Internet]. Palo Alto: Consulting Psychologists Press; 1996 [cited Ago 18, 2019]. Available from: https://www.researchgate.net/profile/Christina_Maslach/ publication/277816643_The_Maslach_Burnout_Inventory_ Manual/links/5574dbd708aeb6d8c01946d7.pdf

13. Griep RH, Rotenberg L, Vasconcellos AGG, Landsbergis P, Comaru CM, Alves MGM. The psychometric properties of demand-control and effortreward imbalance scales among Brazilian nurses. Int Arch Occup Environ Health. 2009;82(10):1163-72. doi: http://dx.doi.org/10.1007/ s00420-009-0460-3

14. Fávero B, Migott AMB. Labor nurses activity and the relationship with the burnout syndrome: integrative review. Enferm Bras. 2017 Oct;16(6):391-402. doi: http:// dx.doi.org/10.33233/eb.v16i6.1036

15. Schadenhifer $P$, Kundi $M$, Abrahamian $H$, Stummer $H$, Kautzky-Willer $A$. Influence of gender, working field and psychosocial factors on the vulnerability for burnout in mental hospital staff: results of an Austrian cross-sectional study. Scand J Caring Sci. 2018 Mar;32(1):335-45. doi: http://dx.doi.org/10.1111/scs.12467

16. Matos IB, Toassi RFC, Oliveira MC. Health Professions and Occupations and Feminization Process: Trends and Implications. Athenea Digital. [Internet]. 
2013 July [cited Oct 16, 2019];13(2):239-44. Available from: https://www.lume.ufrgs.br/bitstream/ handle/10183/118035/000894801. pdf?sequence $=1$

17. Trindade LL, Lautert L. Syndrome of Burnout among the workers of the Strategy of Health of the Family. Rev Esc Enferm USP. 2010 Jun;44(2):274-9. doi: http://dx.doi. org/10.1590/S0080-62342010000200005

18. Salmela-Aro K, Upadyaya K. Role of demandsresources in work engagement and burnout in different career stages. J Vocat Behav. 2018 Oct;108:190-200. doi: http://dx.doi.org/10.1016/j.jvb.2018.08.002

19. Madsen IEH, Lange T, Borritz M, Rugulies R. Burnout as a risk for antidepressant treatment- a repeated measure time-to-event analysis of 2,936 Danish human service workers. J Psychiatr Res. 2015 Jun;65:47-52. doi: http:// dx.doi.org/10.1016/j.jpsychires.2015.04.004

20. Santos AYR, Esquivel AD, Granillo JF, Sánchez JÁ, Alejo GC. Prevalence of burnout in health personnel in critical areas and its association with anxiety and depression. An Med (Mex). [Internet]. 2018 Nov [cited Sept 16, 2019];63(4):246-54. Available from: https:// www.medigraphic.com/pdfs/abc/bc-2018/bc184b.pdf 21. Choi BS, Kim JS, Lee DW, Paik JW, Lee BC, Lee JW, et al. Factors Associated with Emotional Exhaustion in South Korean Nurses: A Cross-Sectional Study. Psychiatry Investig. 2018 July;15(7):670-6. doi: http://dx.doi. org/10.30773/pi.2017.12.31

22. Portoghese I, Galleta M, Leiter MP, Cocco P, D'Aloja E, Campagna M. Fear of future violence at work and job burnout: A diary study on the role of psychological violence and job control. Burnout Res. 2017 Dec;7:36-46. doi: http://dx.doi.org/10.1016/j.burn.2017.11.003

23. Ferreira AP. Satisfaction, workload and stress among providers of a mental health services. Rev Bras Med Trab. [Internet]. 2015 Mar [cited Oct 18, 2019];13(2):91-9. Available from: http://files.bvs.br/ upload/S/1679-4435/2015/v13n2/a5236.pdf

24. Rozman M, Grinkevich A, Tominc P. Occupational Stress, Symptoms of Burnout in the Workplace and Work Satisfaction of the Age-diverse Employees. Organizacija. 2019 Feb;52:46-59. doi: http://dx.doi.org/10.2478/orga2019-0005

25. Dias GC, Furegato ARF. Satisfaction in, and impact of work on, the multidisciplinar team in a psychiatric hospital. Rev Enferm UERJ. 2016;24(1):1-7. doi: http:// dx.doi.org/10.12957/reuerj.2016.8164

26. Montgomery A, Spânu F, Baban A, Panagopoulou E. Job demands, burnout, and engagement among nurses: A multilevel analysis of ORCAB data investigating the moderating effect of teamwork. Burnout Res. 2015 Sep;2(2-3):71-9. doi: http://dx.doi.org/10.1016/j. burn.2015.06.001
27. Konstantinou AK, Bonotis K, Sokratous M, Siokas V, Dardiotis E. Burnout Evaluation and Potential Predictors in a Greek Cohort of Mental Health Nurse. Arch Psychiatr Nurs. 2018 Jun;32(3):449-56. doi: http://dx.doi.org/10.1016/j. apnu.2018.01.002

28. Stahl ACF, Stahl C, Smith P. Longitudinal association between psychological demands and burnout for employees experiencing a high versus a low degree of job resources. BCM Public Health. 2018 July 25;18:915. doi: http:// dx.doi.org/10.1186/s12889-018-5778-x

29. Negussie N, Kaur G. The Effect of Job DemandControl-Social Support Model on Nurses' Job Satisfaction in Specialized Teaching Hospitals, Ethiopia. Ethiop J Health Sci. 2016 July;26(4):311-20. doi: http://dx.doi. org/10.4314/ejhs.v26i4.3

30. Gerich J, Weber C. The Ambivalent Appraisal of Job Demands and the Moderating Role of Job Control and Social Support for Burnout and Job Satisfaction. Soc Indic Res. 2019 Oct 11. doi: http://dx.doi.org/10.1007/ s11205-019-02195-9

31. Pinto JK, Dawood S, Pinto MB. Project management and burnout: Implications of the Demand-Control-Support modelo on project-based work. Int J Proj Manag. 2014 May;32(4):578-89. doi: http://dx.doi.org/10.1016/j. ijproman.2013.09.003

32. Hadžibajramović E, Ahlborg G Jr, Grimby-Ekman A. Concurrent and lagged effects of psychosocial job stressors on symptoms of burnout. Int Arch Occup Environ Health. 2019 May;92(7):1013-21. doi: http://dx.doi.org/10.1007/ s00420-019-01437-0

33. Duan X, Ni X, Shi L, Zhang L, Ye Y, Mu H, et al. The impact of workplace violence on job satisfaction, job burnout, and turnover intention: the mediating role of social support. Health Qual Life Outcomes. 2019;17(1):93-103. doi: http://dx.doi.org/10.1186/ s12955-019-1164-3

34. Liao RW, Yeh ML, Lin KC, Wang KY. A Hierarchical Model of Occupational Burnout in Nurses Associated with Job-Induced Stress, Self-Concept, and Work Environment. J Nurs Res. 2019 Oct 17. doi: http://dx.doi.org/10.1097/ JNR.0000000000000348

35. Naceur A, Zriba N. Burnout and Coping in the Perspective of Job Demands-Control-Support Model among Nurses. Psychology. 2015 Nov;6:1841-9. doi: http:// dx.doi.org/10.4236/psych.2015.614180

36. Pisanti R, van der Doef M, Maes S, Meier LL, Lazzari $D$, Lazzari D, et al. How Changes in Psychosocial Job: Characteristics Impact Burnout in Nurses: A Longitudinal Analysis. Front Psychol. 2016 July; 7:1082. doi: http:// dx.doi.org/10.3389/fpsyg.2016.01082

37. Castro JF, Zaragoza FM, Rovira T, Edo S, Puchol AS, Martín-del-Río B, et al. How does emotional exhaustion influence work stress? Relationships between stressor 
appraisals, hedonic tone, and fatigue in nurses daily tasks: A longitudinal cohort study. Int J Nurs Stud. 2017 July;75:43-50. doi: http://dx.doi.org/10.1016/j. ijnurstu.2017.07.002

38. Aronsson G, Theorell T, Grape T, Hammarström A, Hogstedt C, Marteinsdottir I, et al. A systematic review including meta-analysis of work environment and burnout symptoms. BMC Public Health. 2017 Mar;17(1):264. doi: http://dx.doi.org/10.1186/s12889-017-4153-7

39. Carlotto MS, Dias S, Batista J, Diehl L. A autonomia desempenha um papel de mediação entre as sobrecarga de trabalho e a síndrome de burnout? In: Lobo F, ed. Psicologia do Trabalho e das Organizações: Contributos. [Internet]. Braga: Axioma; 2016 [Acesso 16 out 2019]. Disponível em: https://www.publicacoesfacfil.pt/product. php?id_product $=889$

40. Zeike S, Ansmann L, Lindert L, Samel C, Kowalski C, Pfaff $H$. Identifying cut-off scores for job demands and job control in nursing professionals: a cross-sectional survey in Germany. BMJ Open. 2018 Sept 26;8:e021366. doi: http://dx.doi.org/10.1136/bmjopen-2017-021366 41. Plaza MJM, Hueso FJC, Boscá NA, Asensi AM, Ferreiro PV, Morales AV, et al. Staff burnout and psychosocial risk factors in a long-stay hospital in Spain. Cad Saude Publica. 2018 Nov 23;34(11):e00189217. doi: http:// dx.doi.org/10.1590/0102-311X00189217

42. Lopes SV, Silva MCD. Occupational stress and associated factors among civil servants of a federal university in the South of Brazil. Cienc Saude Colet. 2018 Nov;23(11):3869-80. doi: http://dx.doi. org/10.1590/1413-812320182311.28682015

43. Broek AV, Elst TV, Billien E, Sercu M, Schouteden M, Witte $\mathrm{H}$, et al. Job Demands, Job Resources, Burnout, Work Engagement, and Their Relationships: An Analysis Across Sectors. J Occup Environ Med. 2017 Apr;59(4):269-76. doi: http://dx.doi.org/10.1097/JOM.0000000000000964 44. Ariza-Montes A, Arjona-Fuentes JM, Han H, Law R. Work environment and well-being of different occupational groups in hospitality: Job Demand-Control-Support model. Int J Hosp Manag. 2018 Jan;73:1-11. doi: http://dx.doi. org/10.1016/j.ijhm.2018.01.010

45. Moura DCA, Greco RM, Paschoalin HC, Portela LF, Arreguy-Sena C, Chaoubah A. Psychological demand and control of the work process of public university servants. Cienc Saúde Coletiva. 2018 Feb;23(2):481-90. doi: http:// dx.doi.org/10.1590/141381232018232.13892015
46. Urbanetto JS, Magalhães MCC, Maciel VO, Sant'Anna VM, Gustavo AS, Figueiredo CEP, et al. Work-related stress according to the demand-control model and minor psychic disorders in nursing workers. Rev Esc Enferm USP. 2013 Oct;47(3):1186-93. doi: http://dx.doi.org/10.1590/ S0080-623420130000500024

47. Silva JLL, Soares RS, Costa FS, Ramos DS, Lima FB, Teixeira LR. Psychosocial factors and prevalence of burnout syndrome among nursing workers in intensive care units. Rev Bras Ter Intensiva. 2015 Apr-Jun;27(2):125-33. doi: http://dx.doi.org/10.5935/0103507X.20150023

48. Heidari Pahlavian A, Gholami T, Heidari Moghaddam R, Akbarzadeh M, Motamedzedh M. Demand-Control Model and its Relationship with Burnout Syndrome in Nurse. J Fasa Univ Med Sci. [Internet]. 2015 March [cited 15 Oct, 2019];5(1):23-35. Available from: http://journal.fums. ac.ir/article-1-459-en.pdf

49. Silva JLL, Teixeira LR, Soares RS, Costa FS, Aranha JS, Teixeira ER. Job Strain and psychosocial aspects of intensive care nurses. Enfermería Global. 2017 Oct;48:94-107. doi: http://dx.doi.org/10.6018/eglobal.16.4.249321

50. Ahola K, Toppinen-Tanner S, Seppänen J. Interventions to alleviate burnout symptoms and to support return to work among employees with burnout: Systematic review and meta-analysis. Burnout Res. 2017 Mar;4:1-11. doi: https://doi.org/10.1016/j.burn.2017.02.001

Received: Feb $1^{\text {st }} 2020$ Accepted: Apr 19 2020

Associate Editor:

Maria Lúcia do Carmo Cruz Robazzi

Copyright $(92020$ Revista Latino-Americana de Enfermagem This is an Open Access article distributed under the terms of the Creative Commons (CC BY).

This license lets others distribute, remix, tweak, and build upon your work, even commercially, as long as they credit you for the original creation. This is the most accommodating of licenses offered. Recommended for maximum dissemination and use of licensed materials. 